УДК 811.161 .1

DOI 10.18413/2712-7451-2020-39-1-90-99

\title{
ФОРМАТ РАЗВЛЕКАТЕЛЬНОГО РАДИО КАК ФАКТОР, ОПРЕДЕЛЯЮЩИЙ РЕЧЕВУЮ КУЛЬТУРУ РАДИОЖУРНАЛИСТА (НА ПРИМЕРЕ РАДИО «ЕВРОПА ПЛЮС»)
}

\author{
ENTERTAINMENT RADIO FORMAT \\ AS A FACTOR DEFINING THE SPEECH CULTURE OF A RADIO JOURNALIST \\ (USING THE EXAMPLES OF "EUROPA PLUS" RADIO)
}

\author{
А.В. Ельникова, Е.А. Беспалова \\ A.V. Elnikova, E.A. Bespalova
}

Юго-западный государственный университет, Россия, 305040, г. Курск, ул. 50 лет Октября, 94

Southwest State University, 94, 50 Let Oktyabrya St, Kursk, 305040, Russia

E-mail: elnikova2000@icloud.com, kbespalova@yandex.ru

\begin{abstract}
Аннотация
Радикальные преобразования, предопределившие изменения типа и концепции отечественного радиовещания, перестроившие содержание вещания и отношения с аудиторией, отразились и на жанровой структуре современного радио - востребован непринужденный стиль ведения программ, выбор которого может быть обусловлен форматом радиостанции. При этом профессиональная компетентность специалистов, вступающих в диалог с массовым слушателем и во многом формирующих речевую культуру своих многочисленных собеседников, зачастую является сомнительной. Названная область является достаточно новой для изучения, требует отдельного рассмотрения. В связи с этим авторами проведен анализ влияния формата развлекательного радио на коммуникативные качества радиожурналиста и используемые им приемы организации эфира. На основе наблюдения за эфирами утреннего шоу «Бригады У» радио «Европа Плюс», обобщения и интерпретации полученных данных проанализированы специфика речевой культуры ведущего развлекательной радиостанции. Показано, что рамки речевой компетентности ведущего определяет задача производства развлекательного медиатекста. Описаны коммуникативные ролифункции ведущих; типичные коммуникативные стратегии и тактики, используемые в эфире. Рассмотрены проявления речевой культуры ведущих развлекательного шоу на радио, выявлены ее слабые и сильные стороны. В результате выявлены содержательные, структурные и языковые особенности построения коммуникации на развлекательном радио.
\end{abstract}

\begin{abstract}
Far-reaching reforms, predetermined changes in the type and concepts of local radiobroadcasting and restructured the content of broadcast and the relationship with the audience, reflected on the genre structure of modern radio. Nowadays relaxed style of broadcasting is popular and the choice of this style may be due to the format of the following radio station. At the same time, the professional competence of specialists who enter into a dialogue with a mass audience and mainly form the speech culture of their numerous interlocutors is often questionable. This area is new enough to study and requires individual consideration. In connection with this, the authors analyzed the influence of the entertainment radio format on the communicative qualities of a radio journalist and the techniques used for organizing the broadcast. On the basis of the observation of morning shows "Team U" to radio "Europe Plus", consolidation and interpretation of obtained data the specificity of the speech culture of the entertainment radio station's host is analyzed. It is shown that the scope of the speech competence of the presenter is determined by the task of pro-
\end{abstract}


ducing entertainment media text. The article describes the communicative roles and functions of hosts; typical communication strategies and tactics which are broadcast. The article considers the manifestations of the speech culture of the entertainment show hosts on the radio, and reveals its weaknesses and strengths. As a result, the content, structure, and language features of building communication on entertainment radio are revealed.

Ключевые слова: речевая коммуникация, организация эфира, радиожурналистика, развлекательный формат радио.

Key words: speech communication, broadcast organization, radio journalism, entertainment format of radio.

\section{Введение}

Новые социально-политические условия, технологические возможности предопределили смену функций радиожурналиста, изменение характера взаимоотношений ведущего и аудитории и, как следствие, изменение требований к коммуникативной и речевой культуре радиожурналиста. Важнейшими навыками на радиостанциях любого формата (и особенно развлекательного) является умение организовывать, вести и контролировать «живой», общеинтересный диалог в прямом эфире. Радикальные преобразования, предопределившие изменения типа и концепции отечественного радиовещания, перестроившие содержание вещания и отношения с аудиторией, отразились и на жанровой структуре современного радио. Идет обратное движение от сложных жанровых форм к обычному речевому общению, размываются границы жанров, корректируются критерии эффективности коммуникации в отношении классических радиожанров.

Профессиональная компетентность специалистов, вступающих непосредственно в диалог с массовым слушателем и во многом формирующих речевую культуру своих многочисленных собеседников, зачастую является сомнительной. При этом значительно снижается интерес слушателей к образованным, интеллигентным ведущим, мастерски владеющим голосом и речевыми нормами. Востребован живой, непринужденный стиль ведения программ, выбор которого может быть обусловлен форматом радиостанции или противоречить ему. Названная область является достаточно новой для изучения, требует отдельного рассмотрения.

Цель данной работы - выявление и описание специфики коммуникативных навыков журналиста радио развлекательного формата, особенностей его речевого этикета на основе наблюдения, обобщения полученных данных, качественной интерпретации данных.

\section{Формат развлекательного радио и условия успешной коммуникации}

Специфика радийной коммуникации является важным направлением современной медиалингвистики. Ее изучению посвящено множество научных трудов [Сомова, 2002; Босый, 2006; Język w media, 2012; Коньков, 2016; Беспалова, Ельникова 2019; Зубко, 2019]. Особенности развлекательного радийного радиодискурса на сегодняшний день описаны фрагментарно, основные направления исследования только формируются [Болотова, 2000; Фащанова, 2012; Чернышов, 2013], поэтому при проведении исследования важно учитывать тенденции, которые доминируют в теории медиа в целом [Васильев, 2003]. Принципиально значимы представления о том, что на радио существенны два полярных речевых замысла - фатика и информатика, где, согласно оценке Т.Г. Винокур, под фатикой понимается «вступление в общение, имеющее целью предпочтительно само общение» [1993, с. 136]. Примером реализации фатической функции коммуникации (общение ради общения) является small talk [Степыкин, 2010; 2014] 
Речевую компетентность можно характеризовать как тематически сфокусированную, социокультурно обусловленную речемыслительную деятельность, предопределенную спецификой радиодискурса: информационно-аналитического или развлекательного.

В качестве исследовательской базы были выбраны прямые эфиры утренних программ «Бригады У» радио «Европа плюс» и их распечатки- «Европа плюс» - первая в России коммерческая радиостанция, созданная 30 апреля 1990 года, на сегодня вещающая на русском языке в восьми странах ближнего зарубежья. Ее содержательный контент составляют музыкальные и речевые программы фатических жанров.

Основу формата вещания музыкально-развлекательной радиостанции составляют шуточные диалоги, музыкальные заставки, джинглы, отбивки, афоризмы популярных ведущих, телефонные разговоры со слушателями и др., что фактически провоцирует, «требует» от ведущих отступления от некоторых норм, обязательных для соблюдения в других СМИ. Как замечает Т.П. Куранова, «первое впечатление, которое возникает у человека, впервые услышавшего речь ведущего информационно-музыкальной радиостанции, это, как правило, удивление тому, как долго, оказывается, можно говорить, когда сказать, по сути дела, нечего» [Куранова, 2010, с. 213].

«Бригада У» изначально позиционирует себя как коллектив, гарантирующий высокопрофессиональный развлекательный контент. «В арсенале "Бригады У" есть все, что нужно для хорошего начала дня: неслабые шутки, отвязные розыгрыши, свежие темы, музыки больше, чем в айподе. Новости такие, что френдлента отдыхает. А по пятницам вообще сплошное веселье. "Бригада У" легко заменяет двойной капучино, апельсиновый фреш и полчаса отжиманий. Утро с Джемом, Ильей (сейчас его заменил Вэл) и Вики 100 \% гарантия отличного настроения на весь день» ("Европа плюс", 07.12.2018). Джем, Илья и Вики - эфирные имена журналистов, ведущих эту программу.

Как видим, рамки речевой компетентности ведущего в данном случае определяет задача производства развлекательного медиатекста. Радиоведущий в прямом эфире должен создавать авторский текст, креолизованный по фактуре, диалогичный по природе, а по тематической доминанте его «можно отнести к медиатопикам, объединяющим в себе ряд совершенно различных тем» [Чичерина, 2007, с. 164].

Залогом эффективности коммуникации в таком радийном формате являются следующие параметры речевой грамотности: осознание цели, языковое воплощение, общая тональность текста и т.д. В соответствии с этими требованиями выстраивается не только рекламная заставка, но и программы названной группы журналистов. В ходе работы были прослушаны 30 утренних эфиров программы «Бригада У», и в каждом из них отмечена установка на развлечение адресата, что проявлено в подчеркнуто эмоциональной, взволнованно-позитивной тональности диалога. В студии работает слаженный коллектив, и хотя текст программы рождается спонтанно, строится по преимуществу на разговорных конструкциях, оценочных, императивных предложениях, в репликах преобладают яркие выразительные средства.

Известно, что «радиокоммуникация протекает в особых условиях, среди которых можно отметить дистантность, опосредованность, отсутствие визуализации, массовость аудитории, всеохватность, высокую скорость передачи информации, необратимость, одномоментность, непрерывность, линейность» [Нестерова, 2011, с. 37]. Но благодаря ярким индивидуальностям ведущих эти проблемы довольно удачно разрешаются. Несмотря на неподготовленный характер речи, ее демонстративную неофициальность, стремление «говорить обо всем, что приходит в голову» - качества, которые еще несколько десятилетий были невозможны на отечественном радио, считались признаком профессиональной некомпетентности, - «Бригада У» успешно лидирует в своей жанрово-тематической нише, сохраняя высокие места в рейтингах популярности, так как выполняет главную задачу удовлетворяет потребность в общении. 
Коммуникативный замысел задает набор речевых приемов, трансформирует границы языковой нормы, диктует выбор тех или иных вербальных средств. Коммуникативная установка радиоведущего во многом зависит от профессиональной роли журналиста на радио (информатор, аналитик, модератор), при этом она основывается на общих стандартах речевой культуры радиожурналиста [Беспалова, Карцева, 2016]. В нашем случае радиоведущий выполняет роль развлекателя, способствуя релаксации аудитории, что предопределяет особенности его речи. Эффективная коммуникация в программе «Бригады У» подразумевает способность радиоведущих поддерживать (или имитировать) оживленный, непринужденный диалог на общеинтересные темы со слушателями, которые не ставят себе цели получить какую-либо информацию, а слушают программу для поддержания музыкального или разговорного занимательного «фона».

Таким образом, неинформативная беседа составляет основу коммуникации в данной программе. Эту разновидность общения И.А. Стернин определяет как «взаимно приятный, ни к чему формально не обязывающий разговор на общие темы, основная цель которого - провести время с собеседником, оставаясь с ним в вербальном контакте» [Стернин, 1996, с. 14]. Цель такой беседы - «светская болтовня», поэтому темы вовсе не обязательно связываются с актуальной информационной повесткой. Более того, они легко меняются в зависимости от общего хода беседы, что, конечно же, требует от ведущих коммуникативной мобильности.

Необходимо учитывать тот факт, что на радио фактически нет «запретных» тем, стерлись грани между подходящими и неподходящими предметами для обсуждения, так что И.А. Стернин даже предлагает выделить новый жанр радиожурналистики - «треп» в эфире [Стернин, 1996, с. 10]. Такой формат общения требует от ведущих умения «установить, а затем либо продлить, либо прервать общение, то есть проверить, работает ли канал связи, а также для того, чтобы привлечь внимание собеседника и удержать его в случае надобности» [Дементьев, 1999, с. 37]. Для установления непринужденного контакта со слушателем в таких случаях требуется определенное речевое поведение, освоение ряда коммуникативных ролей-функций: «говорю "от себя", как отдельная личность (не несу ответственности за других); обособляю свой групповой опыт (говорю, как принято "у нас"); нейтрализую разные речевые опыты (выравниваю неравные отношения); формирую при этом бесконфликтную стилевую фигуру ("перевожу", строю синонимический ряд)» [Рабенко, 2014, с. 52].

\section{Коммуникативные особенности организации эфира радио «Европа Плюс»}

Специфика речевого общения команды «Бригада У» во многом обусловлена временем выхода программы - это утреннее шоу, призванное помочь весело начать день, «будить Россию». Отсюда и особые формы приветствия: «Пора просыпаться! "Бригада У" - уже в студии Европь Плюс» (08.02.2019); «Утро должно начинаться с позитива - Включай "Бригаду У"» (01.02.2019); «Эксклюзив! "Бригада У" и \#Swanky Tunes создали этот опасный трек для тех, кому надо быстро проснуться! Встречайте!» (19.01.2019); «В "Бригаде У"! Итальянцы!! Мы помним о вас! Встречайте! Итальянская версия тренда Фиги панталони!» (29.01.2019) и др.

Музыкальные заставки переплетаются в эфире с речью ведущих, которые анонсируют события, читают СМС-сообщения и сообщения из социальных сетей, принимают звонки слушателей в прямом эфире, разыгрывают билеты на концерты и развлекательные мероприятия. Доминирующей стратегией в таких случаях является побуждение к действию, привлечение внимания, активное включение аудитории в процесс саморазвлечения.

Радиоведущие предлагают присылать сообщения, звонить, высказываться по поводу, спеть в эфире и т.д. Как указывает В.А. Егошкина, данные «коммуникативные стратегии реализуются в речи ведущих посредством использования следующих тактик: приглашение слушать эфир (или иным образом участвовать в передаче), анонс программы или ее 
отдельных компонентов (специальных мероприятий), тактика приглашения к совместным действиям, реализуемая за счет шаблонных выражений ("давайте мыл", "оставайтесь $c$ нами", "давайте вместе", использования императивных форм глаголов ("участвуйте в наших проектах", "звоните в эфир" и др.), тактики креативной адресации, подразумевающие использование нестандартных методов и форм обращения к слушателям, тактика самопрезентации ведущего или слушателя, эмоционально настраивающие тактики, диалоговые тактики [Егошкина, 2014, с. 186].

Это означает, что для успешного контакта с аудиторией ведущий должен уверенно владеть речевыми тактиками, лежащими в основе императивных жанров. Он должен умело побуждать к определенному, выгодному для журналиста типу поведения, реагирования. К примеру, «Участвуй в игре "Королевская гонка в Бригаде У", получи путевку в Сочи $и$ отправляйся вместе с Джемом, Ильей и Вики на легендарный чемпионат мира по шоссейно-кольцевым автогонкам! "Бригада У" ждет твоего звонка по телефону (495) 745-65-65. Пройди испытание на скорость в утреннем эфире Европы Плюс! На кону: билет на Сочи Автодром. Дерзай, и да пребудет с тобой жажда скорости!» (09.03.2019). Общеупотребительность таких форм подтверждают и другие примеры.

Отдельные разделы эфира строятся на прямом привлечении к регулярному прослушиванию программы. Аудитории настойчиво предлагают материальный стимул, участие в розыгрыше денежного приза для слушателей. Так, в структуру утреннего шоу «Бригады У» входит программа «Сейф», ежедневно слушателем предлагается «взломать сейф» и «забрать» деньги. По мере того, как растет сумма в сейфе, нарастает экспрессия приглашений позвонить в студию. Этот раздел существует в эфире долгое время, соответственно, сложилась огромное количество подводок-приглашений к участию: «B ceŭфе "Бригады У" скопилась внушительная сумма - 80000 рублей!.. Угадай код и сорви большой куш!» (29 .02. 2019); «Хочешь тоже сорвать большой куш и попасть в галерею лучших "грабителей" на сайте "Бригады У"? Джем, Илья и Вики ждут твоего звонка каждый будний день в 9:35 по номеру (495) 745-65-65! Возможно, именно ты станешь одним из самых крутых взломщиков сейфа на Европе Плюс!» (04 .03. 2019) и др.

Речевая культура в программах такого формата предполагает и свободное, творческое оперирование обязательными, ритуальными компонентами: «спасибо за звонок», «оставайтесь с нами», «простите, но ваш ответ неверный», «сегодня не ваш день, деньги остаются в студии», «вы становитесь обладателем двух билетов», «выигрыш ждет вас», «спасибо за участие», «поздравляем победителя» и др. Важно, чтобы эти шаблонные формулы не повторялись в рамках одного эфира, соответствовали характеру собеседника, сопровождались верной интонацией.

Анонсы мероприятий сложны тем, что требуют выделения одного из событий таким образом, чтобы завоевать внимание аудитории, которая слушает радио для развлечения, мало расположена к сосредоточению. Иначе говоря, в фатический текст вторгается информационный компонент и ведущий должен переключить аудиторию «на запоминание», а это требует тонкого владения ораторскими приемами привлечения внимания.

Важным коммуникативным навыком выступает и умение сортировать, отбирать и представлять в эфире присланные СМС-сообщения. Во-первых, нужно уметь охватить весь текст присланного сообщения, ведь отдельные обороты могут быть за пределами речевой нормы, вплоть до нецензурных выражений. В таких случаях, ведущие «Бригады У», как правило, отшучиваются, быстро импровизируют, переводя сообщение в рамки допустимого. Во-вторых, авторы сообщений могут скрываться за совершенно неудобочитаемыми никнеймами, что составляет серьезную сложность в прямом эфире. В таких случаях все трое ведущих переключаются на комментирование ника, языковое обыгрывание имени, выбранного виртуальным коммуникантом. 
Кроме того, в структуру программы входит страничка «Кто здесь?». Принцип ее в том, что журналисты рассылают СМС-сообщения случайным слушателям и затем зачитывают в эфире ответы на них. Здесь эффективность коммуникации во многом зависит от знания аудитории, психологии общения. Чтобы получить интересные ответы, нужно очень точно рассчитать реакцию, выверить текст рассылаемого сообщения. К примеру, 26 апреля 2019 года зрители должны были прислать продолжение СМС-сообщения, в котором был такой текст: «оказывается, все не так, как есть на самом деле...». Комментарии ведущих были минимальны, на уровне эмоциональных эллиптических реплик, просторечных оборотов, которые и являлись основным инструментом удерживания внимания. Журналисты сознательно предельно упрощали комментарии, подстраиваясь под настрой авторов присланных СМС-сообщений и под общий формат шоу.

Не менее важные составляющие речевой культуры на развлекательном радио умение вовлекать слушателя в музыкальные конкурсы, минимальные навыки владения голосом или способность обыграть собственное неумение петь. В рамках проекта «Музи Смузи» радиоведущие предлагают аудитории бесконечные музыкальные эксперименты по исполнению песенных хитов, угадыванию саундтреков, поэтическим импровизациям и т.д. Залогом эффективной коммуникации здесь выступает обаяние ведущих, их умение мгновенно расположить к себе дозвонившегося, который должен сразу же включиться в процесс развлечения слушателей. «В "Бригаде У"! Круто и немножко грустно. Но очень горячо! А ещё там в конце такой гармошечный вобл» (01.02. 2019).

Столь же виртуозного контроля над ситуацией и речевым поведением дозвонившихся требуют от ведущих программы «City battle» (варианты названия «street battle», «family battle»), в ходе которых разворачиваются шуточные состязания между слушателями из разных городов, так как здесь возможны и технические накладки (пропадает звук, посторонние шумы в эфире и др.), и проблемные собеседники.

Исследование показало, что принципиально значимым для эффективной коммуникации является умение быстро переходить от одного предмета обсуждения к другому. Учитывая, что в студии несколько ведущих, эта проблема решается довольно просто: слушатель далеко не всегда может уловить, когда происходит смена темы, диалог длится непрерывно, благодаря отработанным приемам использования речевых фатических жанров:

- воспоминание («Я в детстве, когда сльшила "Пусть бегут неуклюже... ", всегда думала, кто же эти неуклюжи, какие они?» (26.04.2019)),

- вопрос («Какого числа состоялся релиз? Да, может, он вообще еще не состоялcя?» (26.04.2019)),

- сплетня («Для начала. Американец судится за право жениться на макбуке. Это уже вторая его попытка. Полгода назад он пытался жениться на любимом гаджете в штате Флорида. Там ему отказали...» (21.04.2019)),

- анонс («Я иду на... иирк дю Солей и на одно из их красочных шоу Varekai. По всему миру оно идет с большим успехом. В Монреале оно началось, и вот сейчас продолжается в Москве. С 14 апреля можно идти покупать билеты, а можно не покупать, а вылирывать их в "Бригаде У"...» (05.04.2019)),

- обещание, переход от общего к частному («О-о-очень красивый фильм... Все знают, кто он такой и всех его друзей знают и любят. Мне кажется, все в какой-то степени в детстве хотели быть... Давайте знакомиться с нашими... С нашими... С нашими! С нашими игроками»),

- введение в диалог примеров из личного опыта («А у меня одна подруга не только разделяет гаджеты на самочек и самок, но и дает им имена. У нее есть айфон Шар- 
лиз Терон. И я машину называю... Жучок...У меня навигатор съемный был - Глория» (21.04.2019)).

В.А. Егошкина дает классификацию приемов смены темы [Егошкина, 2014, с. 182], и все перечисленные ею риторические ходы отмечены в прослушанных утренних эфирах «Бригады У»: использование вопросов, прогнозов, шуток, слухов и т.д., актуализации информации, известной ведущему, и обращение к собеседнику в студии, введение в диалог личного мнения говорящего, использование прецедентных текстов, использование домашней заготовки (факта неизвестного ранее, но имеющего отношение к обсуждаемому).

Как в передачах развлекательного формата в целом, так и в анализируемых программах речь ведущих спонтанна, она максимально сближается с разговорной. В репликах обычны неологизмы, жаргонные, сленговые выражения, просторечные слова, разговорные частицы, междометия. В ней частотны элементы разговорного синтаксиса, включая этикетные формулы, эллиптические конструкции, не редки случаи отсутствия грамматического согласования членов предложения, вопросно-ответного построения предложения, многократного употребления местоимений, использования вставных конструкций и др.

Независимо от предмета обсуждения, структурного раздела шоу от ведущих требуется неизменно жизнерадостный и непринужденный тон. В рассматриваемой программе он поддерживается за счет активного использования диалогических форм и «позитивных» эпитетов: «Привет! Все готовы к пятнище?», «Доброго вам утра, друзья!» «Отличного всем настроения», "Друзья, всем-всем удачной пятницы» и др.

«Сближение с аудиторией» чаще всего достигается через демонстративное «упрощение» речи, стилистическую подстройку под молодежный сленг, что становится возможным благодаря широкому использованию просторечных оборотов и единиц: «офигеть», «ужос-ужос», «блин», «клёво», «трэи», «прикольно», «класс», «ни чё себе», «ни фига себе» и др.

В широком использовании таких конструкций кроется одна из существенных проблем современных медиа - снижение речевой культуры. С одной стороны, книжная речь мало приспособлена для разговорно-развлекательных форматов, а разговорная ведет к «сильнейшему раскачиванию и расшатыванию литературной нормы» [Лаптева, 2007, с. 7]. С другой - необходимость вести «легкий» разговор в прямом эфире подталкивает журналиста развивать свою речевую индивидуальность с тем, чтобы выделиться, запомниться слушателям. Для Джема, Ильи и Вики таким приемом индивидуализации становятся диалоги между собой, сквозные «внутренние шутки», постоянная ирония в отношении друг друга и введение в программу четвертого ведущего - Ерошки, пса постоянно находящегося в студии, которого позиционируют в качестве равноправного участника эфиров.

Благодаря единой установке на непринужденность, утреннее ток-шоу «Бригады У» воспринимается не как набор случайных сообщений, включая рекламные объявления и музыкальные композиции, адресованные «невзыскательной» аудитории, а как целостный радиотекст, ориентированный на взаимодействие со слушателями, - особым образом организованное коммуникативное пространство радиоэфира.

Как видим, необходимым элементом коммуникативной культуры журналиста развлекательного радио является умение «говорить обо всем», что подразумевает применение оборотов разговорной речи, синтаксических конструкций, свойственных спонтанному говорению, стилистическую неоднородность высказываний, непринужденную интонацию, тематическую свободу, включая смену предмета разговора.

В целом уверенное владение культурой онлайн-коммуникации, свободное использование речевых тактик «подключения» аудитории к прослушиванию передачи и непосредственному участию в ней обусловлено спецификой развлекательного дискурса, форматом утреннего шоу, ориентацией на целевую аудиторию. 


\section{Заключение}

Уровень речевой культуры на той или иной радиостанции заметно связан с форматом вещания. Очевидна тенденция к снижению уровня речевой культуры радиоведущих музыкально-развлекательных радиостанций, проявляющаяся в постоянном нарушении орфоэпических, дикционных, стилистических, интонационных и других правил.

Специфика речевого общения на музыкально-развлекательном радио состоит в том, что ведущие создают иллюзию непрерывного диалога со слушателем благодаря императивным формулам, репликам, обращенным к соведущим, диалогам с дозвонившимися в студию. В отдельных эпизодах фатические функции совмещаются с информационными.

Признаком эффективной коммуникации в таких программах является то, что эфир воспринимается не как случайный набор занимательных «диалогов», а как единое органичное для своего формата коммуникативное единство, ориентированное на развлечение слушателя и создающее у него ощущение душевного комфорта, вызывающее живой эмоциональный отклик.

Спонтанность диалога, непредсказуемость общения, отсутствие предварительной подготовки могут приводить к использованию ведущими музыкально-развлекательной радиостанции «Европа Плюс» речевых оборотов, конструкций, нарушающих языковую норму, или нехарактерных для открытой публичной сферы, что обязывает радиожурналистов строже относиться к требованиям речевого этикета, заниматься повышением общей речевой культуры и контролировать себя в эфирное время.

Сделанные выводы вносят вклад в развитие разделов теории речевой коммуникации и медиалингвистики, связанных со сферой развлекательной радиожурналистики.

\section{Список литературы}

1. Болотова Л.Д. 2000. Радиожурналистика. М., Издательство Московского университета, $480 \mathrm{c}$.

2. Босый П.Н. 2006. Современная радиоречь в аспекте успешности / неуспешности речевого взаимодействия. Автореф. дисс. ... канд. филол. наук. Томск, 23 с.

3. Беспалова Е.А., Ельникова А.В. 2019. Условия успешной речевой коммуникации радиожурналиста (на примере ведущего общественно-политической радиостанции). Научные ведомости Белгородского государственного университета. Серия: Гуманитарные науки, 38 (2): 191-201. DOI 10.18413/2075-4574-2019-38-2-191-201

4. Беспалова Е.А., Карцева О.В. 2016. Влияние фактора профессиональной специализации радиожурналиста на его коммуникативную культуру. В кн.: Новый взгляд на проблемы современного языкознания. Материалы VII Международной научной конференции школьников, студентов и аспирантов. Под ред. Н.А. Боженкова. Курск, Юго-Западный государственный университет: 24-29.

5. Васильев А.Д. 2003. Слово в российском телеэфире. М., Флинта, Наука, 224 с.

6. Винокур Т.Г. 1993. Говорящий и слушающий. Варианты речевого поведения. М., Наука, $172 \mathrm{c}$.

7. Дементьев В.В. 1999. Фатические речевые жанры. Вопросы языкознания, 1: 37-55.

8. Егошкина В.А. 2014. Прагмастилистическая специфика развлекательного радийного дискурса. Коммуникативные исследования, 2: 181-188.

9. Зубко Д.В. 2019. Радиопублицистика России: проблемно-тематические и структурнофункциональные характеристики (2000-2018). Автореф. дисс. ... канд. филол. наук, Москва, 34 с.

10. Коньков В.И. 2016. Медиаречь: содержание понятия и принципы анализа. Мир русского слова, 3: 58-63.

11. Куранова Т.П. 2010. Языковая игра в речи ведущих радиопрограмм. Ярославский педагогический вестник, 1: 213-217.

12. Лаптева О.А. 2007. Живая русская речь с телеэкрана. М., Издательство ЛКИ, 517 с.

13. Нестерова Н.Г. 2011. Коммуникативно-прагматический потенциал оценки в речи радиоведущего. Вестник Томского государственного университета, 353: 30-33. 
14. Рабенко Т.Г. 2014. Фатика и средства ее реализации в радиоэфире. Вестник Томского государственного университета, 3 (29): 50-59.

15. Сомова Е. Г. 2002. Языковая метафора в радиоречи. Автореф. дисс. ... канд. филол. наук, Краснодар. 20 с.

16. Степыкин Н.И. 2010. Small talk как стереотип вербального поведения. Вестник Московского государственного лингвистического университета. Языковое существование человека и этноса, 5 (584): 207-217.

17. Степыкин Н.И. 2014. Small talk: рекомендуемые и конвенционально запрещенные темы (на материале английского языка). Известия Юго-Западного государственного университета. Серия Лингвистика и педагогика, 4: 25-29.

18. Стернин И.А. 1996. Светское общение. Воронеж, Рико, 18 с.

19. Фащанова С.В. 2012. Языковая игра в радиодискурсе: коммуникативнопрагматический аспект. Автореф. дисс. ... канд. филол. наук. Томск, 24 с.

20. Чернышов А.В. 2013. Медиамузыка: основы теории, практика и история. Автореф. дисс. ... докт. филол. наук. Москва, 42 с.

21. Чичерина Н.В. 2007. Типология медиатекстов как основа формирования медиаграмотности. Известия российского государственного педагогического университета имени А.И. Герцена, 47 (9): 159-166.

22. Język w mediach. 2012. Katowice, Wyd-wo Uniwersytetu Śląskiego, 312 p. (in Polish).

\section{References}

1. Bolotova L.D. 2000. Radiozhurnalistika [Radio journalism]. Moscow, Izdatel'stvo Moskovskogo universiteta, $480 \mathrm{p}$.

2. Bosyj P.N. 2006. Sovremennaya radiorech' v aspekte uspeshnosti / neuspeshnosti rechevogo vzaimodejstviya [Modern radio speech in terms of success / failure of speech interaction]. Abstract. diss. ... cand. filol. sciences. Tomsk, 23 p.

3. Bespalova E.A., El'nikova A.V. 2019. Conditions for successful speech communication of radio journalists (on the example of the leading socio-political radio station). Belgorod State University Scientific bulletin. Humanities, 38 (2): 191-201. (in Russian). DOI 10.18413/2075-45742019-38-2-191-201

4. Bespalova E.A., Karceva O.V. 2016. Vliyanie faktora professional'noj specializacii radiozhurnalista na ego kommunikativnuyu kul'turu [Influence of the factor of professional specialization of a radio journalist on his communicative culture]. In: Novyj vzglyad na problemy sovremennogo yazykoznaniya [A new look at the problems of modern linguistics]. Materialy VII Mezhdunarodnoj nauchnoj konferencii shkol'nikov, studentov i aspirantov. Kursk, Yugo-Zapadnyy gosudarstvennyy universitet: $24-29$.

5. Vasil'ev A.D. 2003.Slovo v rossijskom teleefire [The word in Russian television]. M., Flinta, Nauka, 224 p.

6. Vinokur T.G. 1993. Govoryashchij i slushayushchij. Varianty rechevogo povedeniya [Talking and listening. Speech Options]. M., Nauka, 172 p.

7. Dement'ev V.V. 1999. Faticheskie rechevye zhanry [Fatal Speech Genres]. Voprosy yazykoznaniya, 1: 37-55.

8. Egoshkina V.A. 2014. Pragmastilisticheskaya specifika razvlekatel'nogo radijnogo diskursa [Pragmatic stylistic features of entertainment radio discourse]. Kommunikativnye issledovaniya, 2: 181-188.

9. Zubko D.V. 2019. Radiopublicistika Rossii: problemno-tematicheskie i strukturnofunkcional'nye haraktersitiki (2000-2018) [Radio journalism of Russia: problem-thematic and structuralfunctional characteristics (2000-2018)]. Abstract. diss. ... cand. filol. sciences, Moscow, $34 \mathrm{p}$.

10. Kon'kov V.I. 2016. Mediarech': soderzhanie ponyatiya i principy analiza [Media Speech: content of the concept and principles of analysis]. Mir russkogo slova, 3: 58-63.

11. Kuranova T.P. 2010. Yazykovaya igra v rechi vedushchih radioprogramm [Language game in speech of leading radio programs]. Yaroslavskij pedagogicheskij vestnik, 1: 213-217.

12. Lapteva O.A. 2007. Zhivaya russkaya rech's teleekrana [Live Russian speech from the TV screen]. M., Izdatel'stvo LKI, 517 p. 
13. Nesterova N.G. 2011. Kommunikativno-pragmaticheskij potencial ocenki v rechi radiovedushchego [Communicative-pragmatic assessment potential in the speech of the radio host]. Vestnik Tomskogo gosudarstvennogo universiteta, 353: 30-33.

14. Rabenko T.G. 2014. Fatika i sredstva ee realizacii v radioehfire [Fatika and the means of its implementation on the air]. Vestnik Tomskogo gosudarstvennogo universiteta, 3 (29): 50-59.

15. Somova E. G. 2002. Yazykovaya metafora v radiorechi [Language Metaphor in Radio Speech]. Abstract. diss. ... cand. filol. sciences, Krasnodar, 20 p.

16. Stepykin N.I. 2010. Small talk kak stereotip verbal'nogo povedeniya. [Small talk as a Stereotype of Verbal Behaviour]. Vestnik of Moscow State Linguistic University. Language Existence of Man and Ethnos, 5 (584): 207-217.

17. Stepykin N.I. 2014. Small talk: rekomenduemye i konvencional'no zapreshchennye temy (na materiale anglijskogo yazyka) [Small Talk: Recommendeded and Conventionally Forbidden Topics (in English)]. Proceedings of South-West State University. Series Linguistics and Pedagogics, 4: 25-29.

18. Sternin I.A. 1996. Svetskoe obshchenie [Secular communication]. Voronezh, Riko, 18 p.

19. Fashchanova S.V. 2012 Yazykovaya igra v radiodiskurse: kommunikativno-pragmaticheskij aspect [Language game in radio discourse: communicative-pragmatic aspect]. Abstract. diss. ... cand. filol. sciences, Tomsk, $24 \mathrm{p}$.

20. Chernyshov A.V. 2013. Mediamuzyka: osnovy teorii, praktika i istoriya [Media Music: Fundamentals of Theory, Practice and History]. Abstract. diss. ... dokt. filol. sciences, Moscow, 42 p.

21. Chicherina N.V. 2007. Tipologiya mediatekstov kak osnova formirovaniya mediagramotnosti [Typology of media texts as the basis for the formation of media literacy.]. Izvestiya rossijskogo gosudarstvennogo pedagogicheskogo universiteta imeni A.I. Gercena, 47 (9): 159-166.

22. Język w mediach. 2012. Katowice, Wyd-wo Uniwersytetu Śląskiego, 312 p. (in Polish).

\section{Ссылка для цитирования статьи For citation}

Ельникова А.В., Беспалова Е.А. 2020. Формат развлекательного радио как фактор, определяющий речевую культуру радиожурналиста (на примере «Европы Плюс»). Вопросы журналистики, педагогики, языкознания, 39 (1): 90-99. DOI 10.18413/2712-7451-2020-39-1-90-99

Elnikova A.V., Bespalova E.A. 2020. Entertainment radio format as a factor defining the speech culture of a radio journalist (using the examples of "Europa Plus" radio). Issues in Journalism, Education, Linguistics, 39 (1): 90-99 (in Russian). DOI 10.18413/2712-7451-2020-39-1-90-99 